\title{
Prevention of Depression and Psychological Stress by Studying Book in Quarantine Conditions of COVID-19
}

\author{
Marjan Arab-Rahmatipour ${ }^{\mathrm{a}^{*}}$, Alireza Ebadollahi-Natanzi ${ }^{\mathrm{b}}$, \\ Gholamrza Arab-Rahmatipour ${ }^{\mathrm{c}}$ \\ ${ }^{a}$ Department of Communication and Knowledge Sciences, Tehran Science and Research Branch, Islamic Azad University, Tehran, Iran. \\ ${ }^{b}$ Department of Medicinal Plants, Imam Khomeini Higher Education Center, Agricultural Research, Education and Extension \\ Organization (AREEO), Karaj, Iran. \\ ${ }^{c}$ Department of Farabi Hospital Laboratory, Tehran University of Medical Sciences, Tehran, Iran.
}

Received 02 June 2020; Accepted 06 July 2020

\begin{abstract}
With the occurrence pandemic of Coronavirus disease (COVID-19), the World Health Organization and health officials in all countries of the world were forced to comply with quarantine conditions. On the one hand, the stress of this dangerous viral disease, and other hand, staying home for an indefinite period of time does not have pleasant consequences. The announcement of an increase in the number of patients with the disease and the death toll also adds to the emotional excitement. Therefore, to prevent mental and psychological diseases as well as other social harms, people can make it easier and more tolerable of quarantine conditions and issues on the margins of illness, by studying and reading books. Research has shown that studying, especially reading books plays an important role in preventing diseases such as depression and stress. It is difficult to predict when this tragedy will end. But more importantly, the evidence suggests there is a possibility that such cases will be repeated.
\end{abstract}

Keywords: COVID-19; Quarantine; Reading Book; e-Libraries; Depression; Psychological Stress.

\section{Introduction}

In the pandemic of COVID-19, which was announced by the World Health Organization, all sites and media outlets began to report extensively about the pandemic. The news from the statistics of the patients and the dead showed that the situation is very worrying. For this reason, in all countries, it was recommended that all people stay at home for self-care and self-quarantine [1].

Due to the creation of unsafe health environment and the following the quarantine - staying at home - in order to control and inhibitory of disease, the situation may change in some societies and lead to an increase in social harms and exacerbation of family tensions [2]. The quarantine environment may cause illnesses such as anxiety, stress, depression, boredom, and insomnia [3], and they may resort to sedatives and narcotics to relieve these conditions, and this is likely to lead to an increase the incidence of other diseases. Therefore, it is necessary to find a suitable solution for using the time at home so that people can go through the quarantine period more easily. The instrumental use of study in such a situation can be a good opportunity to improve knowledge and avoid the psychological consequences of quarantine. Studying and searching sites, e-libraries, social networks, magazines, etc. makes it possible to turn this important consequence of medical history into an opportunity by increasing knowledge and making optimal use of

* Corresponding author: marabrahmatipour@gmail.com

$>$ This is an open access article under the CC-BY license (https://creativecommons.org/licenses/by/4.0/).

(C) Authors retain all copyrights. 
time, and by creating a self-care culture prevented many social harms. It is expected that at this time in house, many studies will be conducted to find out how to prevention of COVID-19, and this enthusiasm will be an important factor in increasing the level of health and care needed against many diseases. Therefore, the choice of suitable subject and action of the health principles recommended by all the sources searched (scientific / unscientific) is of particular importance.

Nowadays, the Internet and social networks play an important role in the sharing and exchange of knowledge. Therefore, obtaining the correct information is also very important and requires referring to experts in this field [4]. The use of electronic libraries manages by experienced people plays a constructive role during quarantine. With a high level of knowledge of job skills, these people will be a good guide for users and will be able to guide users in the same quarantine location in order to exchange and share knowledge and choose the correct topic. Research suggests that studying and book-therapy play an important role in the prevention of certain diseases, such as Alzheimer's, depression, and insomnia [5]. Of course, different groups, depending on their interests and tastes, will spend their time reading historical books, novels and other books on various topics in their careers. This positive point, that's means getting away from mental and psychology illnesses, by the instrumental use of book and studying, the strength point and ultimate goal of self-medication is in the condition of self-quarantine.

Perhaps, it may seem that with the advent of many tools and also role of communication and social networks, the culture of studying has greatly weakened. But quarantine conditions of COVID-19 have created a good time to revive this ancient culture. Studying and book reading provide a safe and come with relaxation environment, for all ages (children, youth and adults) in quarantine time by creating a space away from the hustle and bustle of culture and the surrounding tensions. At the moment, there is no definite time to the end of this pandemic, and everything depends on personal hygiene and social distance. However, evidence shows that in recent decades, epidemics such as SARS and MERS-CoV, and a dreadful pandemic such as COVID-19, have sometimes they surprise people. Therefore, all people should try to readiness and anticipate such cases, in addition to self-care and health of others, observing all the safety tips recommended by the health care system.

\section{Declaration of Competing Interest}

The authors declare that they have no known competing financial interests or personal relationships that could have appeared to influence the work reported in this paper.

\section{Ethical Approval}

The manuscript does not contain experiments on animals and humans; hence ethical permission not required.

\section{References}

[1] Qazi, A., Qazi, J., Naseer, K., Zeeshan, M., Hardaker, G., Maitama J.Z., ... Haruna, K. (2020). Analyzing situational awareness through public opinion to predict adoption of social distancing amid pandemic COVID-19. Journal of Medical Virology, 1-7. doi: $10.1002 / j m v .25840$.

[2] de Lima, C.A., Alves, P.M.R., de Oliveira, C.J.B., de Oliveira, T.R.N., Barbosa, K.B., Marcene, H.C., ... de Oliveira, S.V. (2020). COVID-19: Isolations, quarantines and domestic violence in rural areas. SciMedicine Journal. 2020;2(1):44-45. doi: 10.28991/SciMedJ-2020-0201-7.

[3] Fardin, M.A. (2020). COVID-19 and anxiety: A review of psychological impacts of infectious disease outbreaks. Archives of Clinical Infectious Diseases. 2020;15(COVID-19):e102779. doi: 10.5812/archcid.102779.

[4] Arab-Rahmatipour, M., Foroutan Rad, L., Mirhosseini, Z., Arab-Rahmatipour, M.J., \& Aghaei, O. (2018). The relationship between optimal use of knowledge and intellectual capital management among library managers of public hospitals. International Journal of Information Science and Management, 16(1), 121-135.

[5] Sahami, M., \& Amini-Manesh, S. (2019). The effectiveness of bibliotherapy on stress, anxiety, and depression in women referring to Shiraz municipality cultural center, Iran. Health Information Managemennt, 16(2): 82-87. doi: 10.22122/him.v16i2.3875. 